Revista de Economia Política, vol. 24, $n^{\circ} 4$ (96), pp. 638-646, outubro-dezembro/2004

\title{
Proposta de Desenvolvimento para o Brasil
}

\author{
Development proposal for Brazil
}

LUIZ CARLOS BRESSER-PEREIRA*

Testimony to the Committee of Economic, Industrial and Trade Development of the House of Deputies.

A economia brasileira encontra-se estagnada há 24 anos, merecendo esse período ser denominado como a Grande Crise. Iniciada em 1980, essa crise não tem precedente na História do Brasil independente: jamais sua renda per capita cresceu menos de um por cento ao ano durante um período tão longo. Em conseqüência, a economia é incapaz de absorver o crescimento da população, e a taxa de desemprego aumenta ano a ano. Quais as razões desse desastre?

Para as compreendermos, é preciso dividir o período em duas partes. Entre 1980 e 1994, a Grande Crise está diretamente relacionada com a crise da dívida externa e com a crise fiscal e se expressa em altas taxas de inflação. A crise da dívida externa é uma crise de solvência da nação como um todo, enquanto a crise fiscal é uma crise do Estado, que traduz o esgotamento do modelo de substituição de importações. Mal ou bem, esses problemas foram enfrentados nos anos 1980 e início dos anos 1990, de forma que estavam razoavelmente equacionados quando o Plano Real afinal logrou estabilizar a alta inflação. A reforma da economia brasileira começou com a bem-sucedida desvalorização cambial de 1983, a partir da qual produziram-se elevados superávits comerciais, teve prosseguimento com a reforma financeira do Ministério da Fazenda que acabou com a multiplicidade de orçamentos (1983-1987); continuou com a renegociação da dívida e a abertura comercial, ambas políticas iniciadas em 1987 e terminadas no início dos anos 1990; e completou-se com a neutralização da inércia inflacionária pelo Plano Real em 1994.

Após a estabilização dos preços, era de se esperar que a economia retomasse o desenvolvimento. Já naquele momento, porém, as agências governamentais e semigovernamentais em Washington e os agentes do sistema financeiro internacio-

\footnotetext{
* Escola de Economia de São Paulo da Fundação Getúlio Vargas. Rua Araripina, 106, São Paulo, SP, Brasil. E-mail: bresserpereira@uol.com.br. Submetido em: junho 2004; aceito: julho 2004.
} 
nal em Nova York (as duas fontes da ortodoxia convencional) propunham aos países emergentes uma nova estratégia de desenvolvimento: 'abrir a conta capital e crescer com poupança externa'. Esta estratégia contrariava e continua a contrariar os mais comezinhos princípios de política econômica, ao partir de um diagnóstico equivocado (os países em desenvolvimento não teriam mais recursos para crescer por conta própria), para propor que o crescimento se realizasse através de mais endividamento (poupança externa), quando muitos desses países - e certamente o Brasil —, não tinham as condições necessárias para que uma estratégia desse tipo fosse bem-sucedida: já estavam excessivamente endividados externamente e não ofereciam aos investidores grandes oportunidades de investimento. A condição para se tornarem merecedores da poupança vinda do Norte, porém, nada tinha a ver com essas duas restrições. Os países deviam lograr 'credibilidade' junto a Washington e Nova York - ou seja, deviam deixar de pensar por conta própria e seguir as políticas recomendadas pelas autoridades em Washington e pelos mercados em Nova York. Quais eram essas políticas? Cada país deveria envolver-se ou aprofundar suas reformas orientadas para o mercado - reformas que resolveriam todos os problemas. Mais especificamente, no caso do Brasil, dever-se-ia (1) adicionar à abertura comercial a total abertura financeira (para que o financiamento pudesse ocorrer livremente no mercado auto-regulado), (2) combater a inflação com ajuste fiscal, (3) com âncora cambial, e, sempre que necessário, (4) com a elevação da taxa de juros básica do Banco Central, Selic. Naquele momento, não se falava ainda de uma política de metas de inflação para o Brasil, já que a principal garantia contra a inflação ficava por conta da âncora cambial.

Dessas quatro recomendações, apenas a do ajuste fiscal era razoável — na verdade, necessária. No plano das contas externas, abrir a conta capital para crescer com poupança externa, ou seja, com déficits em conta corrente, significava perder controle sobre a taxa de câmbio. Significaria, portanto, valorizar cronicamente essa taxa, quando sabemos que os países só alcançam altos níveis de poupança e de crescimento, enquanto mantêm a taxa de câmbio relativamente depreciada. Assim, a política proposta significava destruir o modesto ajuste externo até então logrado, deixando o país mais vulnerável a novas crises de balanço de pagamento. Crises que não tardaram: materializaram-se em 1998 e em 2002. Ainda nesse plano, usar uma âncora cambial como instrumento de combate à inflação significa agravar ainda mais a tendência à valorização da taxa de câmbio embutida na abertura financeira.

Por outro lado, a política monetária, ou, mais precisamente, a combinação da prática de altas taxas de juro básicas pelo Banco Central com a política de se usar essa taxa diante de qualquer elevação da inflação, torna-se um fator fundamental de desequilíbrio da economia brasileira a partir da bem-sucedida depreciação cambial de janeiro de 1999. Com a flutuação do real, terminava a âncora cambial, mas as autoridades econômicas no Banco Central, ainda traumatizadas pela alta inflação de 1980-1994, trataram de substituí-la por uma política de meta de inflação. 
A adoção mecânica dessa política levou e leva ainda o Banco Central a manter essa taxa de juros em um nível mínimo absurdo de $9 \%$ reais, e a aumentar a Selic toda a vez que há uma perspectiva de aumento da inflação, independentemente de sua causa. Suas conseqüências foram desastrosas. Se a crise de balanço de pagamentos de 1998 deveu-se exclusivamente à estratégia de crescimento com poupança externa e à política de âncora cambial, a crise de 2002 deveu-se a um fator político (o temor que a candidatura Lula causava aos mercados financeiros) e à política de meta de inflação que levou o Banco Central, em 2001, a interromper a baixa da taxa básica de juros para evitar a necessária depreciação adicional da moeda que ocorria naquele momento. Essa política não só sinalizou aos credores internacionais que o desequilíbrio fiscal do país continuaria, mas indicou ainda que o governo brasileiro não dava prioridade necessária ao crescente endividamento externo.

A partir de 1999, a taxa de juros básica do Banco Central será o novo instrumento do non-sense. Ela se mantinha muito alta em termos reais desde o final dos anos 1980, e fora elevada de forma violenta e irresponsável em dezembro de 1991, como fruto de um acordo com o FMI. Continuou elevada depois do Plano Real, quando era mais do que razoável que baixasse para níveis civilizados, compatíveis com as classificações de risco do país. Continua elevada até hoje, dificilmente descendo abaixo de $9 \%$ reais. A ortodoxia convencional argumentava e argumenta a favor dessas taxas, dizendo que são necessárias para atrair capitais e para combater a inflação. Na verdade, em relação aos capitais externos, o problema do Brasil (como sabem perfeitamente os países asiáticos, que não estão semi-estagnados) não era e não é o de atraí-los, mas de regular ou estabelecer limites para sua entrada, de forma a manter sua taxa de câmbio competitiva. Em relação à inflação, não há nela nada que justifique os níveis de taxa de juros praticados no Brasil. Podemos discutir, em cada momento do ciclo econômico, se se deve elevar ou baixar a taxa de juros para, respectivamente, combater a inflação de demanda ou para o desemprego, mas para isso não é preciso que o nível da taxa real básica de juros seja 3 a 4 vezes maior do que aquele que prevalece em países com classificação de risco igual ou pior do que as do Brasil.

As causas da crise a partir de 1994, que perdura até hoje, são, portanto, irracionais, se por racional entendermos as políticas públicas voltadas para o interesse nacional. Não há razões para o desastre, há apenas desrazões.

\section{UMA POLÍTICA DE DESENVOLVIMENTO}

O que é preciso fazer para que o Brasil retorne ao desenvolvimento? A ortodoxia convencional e os setores dominantemente rentistas da sociedade (ou seja, cujo rendimento é formado principalmente por juros) afirmam que o mais importante é prosseguir com as reformas. No extremo oposto, velhos desenvolvimentis- 
tas contam com a política industrial — ou seja, com a intervenção do Estado estimulando determinados setores ou empresas estratégicos — para que a retomada do desenvolvimento ocorra.

Os dois grupos têm razão em propor essas políticas, que não são necessariamente contraditórias entre si, mas equivocam-se ao pensar que esta deva ser a prioridade do país e do governo. Não haverá verdadeiro desenvolvimento para o Brasil, enquanto duas mudanças macroeconômicas fundamentais não ocorrerem: enquanto a política de câmbio e a política de taxa básica de juros não mudarem. Ou o país passa a pensar na taxa de câmbio da mesma maneira que fazem os países asiáticos dinâmicos, como uma taxa estratégica que deve ser administrada para permanecer relativamente desvalorizada, e se dá conta que a Selic mínima de $9 \%$ representa uma armadilha da qual o país precisa necessariamente escapar, ou não haverá como o Brasil voltar a se desenvolver de forma sustentada.

Sem dúvida, reformas orientadas para o mercado continuam aconselháveis, mas estão sendo feitas com equilíbrio pelo Congresso, e não podem nem devem ser feitas muito mais depressa do que vem ocorrendo. Sem o necessário debate público sobre elas, o risco de erros de política é muito grande. Definir e aprovar reformas é a função do Congresso Nacional, e o número de reformas já aprovadas desde a Constituição de 1988 é impressionante. Sem dúvida, é preciso muito empenho não apenas para aprovar reformas, mas também para implementá-las.

Veja-se, por exemplo, a Reforma da Gestão Pública de 1995/98, que coube a mim liderar. Só enviei a emenda constitucional para o Congresso depois de amplo debate. E esse debate durou mais três anos até que a emenda fosse aprovada. As principais — não todas - instituições necessárias para essa reforma foram naqueles quatro anos aprovadas. Para isso, houve, depois dos primeiros meses de incompreensão, um grande apoio da sociedade, particularmente, dos altos administradores públicos. Sua implementação, porém, caminha lentamente. Em parte, isso era inevitável, mas não há dúvida que é necessário mais empenho dos governos nessa área. Os ganhos que se podem alcançar nessa área favorecendo o desenvolvimento são extraordinários. A experiência britânica a respeito é clara. Esse país estava ficando para trás na Europa até o final dos anos 1970. Entretanto, graças, principalmente, à grande reforma da gestão pública que empreendeu a partir dos anos 1980, seu desenvolvimento vem sendo extraordinário e conseguiu recuperar plenamente seu atraso de cerca de $30 \%$ do PIB per capita em relação à França e à Alemanha - países que não fizeram sua reforma da gestão pública.

As reformas institucionais são, portanto, necessárias e devem ser continuadas, desde que sua preocupação fundamental não seja simplesmente reduzir o tamanho do Estado, mas lhe dar condições para que desempenhe seu papel de garantir o funcionamento dos mercados e promover a distribuição de renda. $\mathrm{O}$ desenvolvimento só é possível quando o mercado e o Estado são fortes.

Também os desenvolvimentistas têm razão. O Estado brasileiro necessita de 
política tecnológica e industrial. Precisa de mais planejamento do seu desenvolvimento. A política tecnológica vem sendo realizada com competência há bastante tempo, e a política industrial vem afinal ganhando corpo e identidade. $\mathrm{O}$ mesmo ocorre com a política comercial, que é estratégica para o nosso desenvolvimento. Precisamos abrir mercados para nossas exportações não apenas de produtos agrícolas, mas também industriais. Por outro lado, apesar de todas as dificuldades de recursos, desde a transição democrática o país vem realizando avanços extraordinários nas áreas da educação, da saúde, da assistência social, e dos mecanismos de renda mínima. Esses avanços são obviamente necessários para a retomada do desenvolvimento.

Mas é preciso pensar em um novo desenvolvimentismo, que tenha, como uma de suas características, pensar em um grande projeto de desenvolvimento nacional. E que esse projeto ou acordo nacional parta do pressuposto que o setor moderno, capitalista, não tem condições de absorver toda a mão-de-obra excedente do país. Por isso, é preciso que existam políticas de inclusão dos trabalhadores na vida econômica que permitam melhorar suas condições de vida e sua integração ao mercado sem que, para isso, seja necessário se tornarem empregados nas grandes empresas. Nos anos 1950, pensávamos que o desenvolvimento industrial e capitalista absorveria aos poucos a mão-de-obra excedente, mas hoje está claro que isso não é verdade. As tecnologias poupadoras de mão-de-obra avançaram tanto que tiraram das grandes e médias empresas essa capacidade de empregar. Isso, porém, não significa em absoluto que o Brasil, como os demais países, estejam condenados ao desemprego crescente. O desemprego só cresce no Brasil porque o desenvolvimento não acontece.

O novo desenvolvimento deve ocorrer não apenas do alto para baixo, as empresas do setor moderno absorvendo os novos contingentes de mão-de-obra, que chegam todos os anos ao mercado de trabalho, mas também ao próprio nível dos pobres e excluídos. As políticas universais de educação e saúde, as políticas quase universais de renda mínima, têm, naturalmente, um papel essencial. Elas são um mecanismo fundamental de habilitação dos pobres para a sobrevivência em um mercado capitalista duro e implacável. A continuidade da reforma agrária é também plenamente justificável do ponto de vista econômico. O argumento de que ela não é necessária para assegurar o abastecimento interno é correto, mas ela é essencial para integrar na vida social um contingente imenso de cidadãos, garantindo-lhes dignidade pessoal e trabalho. Além disso, é essencial desenvolver mecanismos de crédito a miniempresas, para que pequenos empresários possam surgir nas regiões e bairros pobres. Por outro lado, são fundamentais as políticas mais localizadas, realizadas pelos municípios, como as de urbanização de favelas e o desenvolvimento de atividades sociais e culturais para os pobres.

Através de todas essas iniciativas não se está apenas fazendo 'assistencialismo', como os conservadores gostam de afirmar. Está-se contribuindo efetivamente para o 
desenvolvimento nacional. De duas maneiras: de forma direta, pela elevação do padrão de vida dos pobres - e, afinal, o que é o desenvolvimento senão a elevação sustentada das condições de vida de todos? E, de forma indireta, por meio da redução da concentração de renda, e, portanto, da distância entre as elites e o povo.

No Brasil, a causa mais geral da quase estagnação da economia brasileira por já um quarto de século é essa enorme distância entre o povo e as elites, que as torna alienadas dos problemas nacionais. O modelo desenvolvimentista foi em grande parte vitorioso, principalmente entre 1930 e 1960, porque um grande pacto político popular-nacional aproximou o povo das elites burguesas e tecnoburocráticas, e as tornou engajadas no desenvolvimento do país. Entretanto, a crise desse modelo, nos anos 1980, que poderia ter sido temporária, oferecendo a oportunidade para que algumas mudanças de rumo - principalmente, ajustamento fiscal e reformas orientadas para o mercado - fossem realizadas, afinal, sob o impacto de uma onda ideológica neoliberal e globalista, pregando o Estado mínimo e a irrelevância dos estados nacionais na nova ordem globalizada, levou as elites brasileiras, já afastadas do povo por 20 anos de regime autoritário, a se alienarem, e a perderem o conceito de nação. Esta alienação ocorreu no Brasil, como no resto da América Latina, fundamentalmente no campo da política econômica. No plano das políticas comercial, tecnológica e cultural, o conceito de nação continua vivo. Como continua vivo quando o Brasil participa de competições esportivas. Mas no plano da política de desenvolvimento e de reformas, voltamos, desde os anos 1990, a ignorar os dois princípios básicos do nacionalismo ou do interesse nacional, que nenhum grande país pode ignorar. Acreditamos em algo que os países ricos não cessam de repetir para nós, mas que não praticam - que não há diferença entre o trabalho, o capital e o conhecimento nacionais e os estrangeiros. Praticamente nenhum cidadão dos países que se dizem contrários ao nacionalismo tem dúvida que o dever do seu governo é defender o trabalho e o capital nacionais. E acreditamos que as recomendações de política econômicas vindas do Norte são as melhores, ao invés de pensarmos com nossa própria cabeça. No plano da política macroeconômica, nossa perda do conceito de nação expressa-se principalmente nessa crença de nossas elites de que os países ricos - que as autoridades em Washington e os agentes financeiros em Nova York e demais centros financeiros — saibam melhor do que nós, brasileiros, o que é melhor para o Brasil. Saibam como estabilizar a economia, saibam como equilibrar as contas externas e as contas públicas do país, saibam como combater a inflação. Quando se deixa de diferenciar capital e trabalho nacionais, quando se deixa de pensar com a própria cabeça, deixou-se de ter uma nação. E quando não se tem uma nação, não se tem uma estratégia de desenvolvimento. Só por acaso e de forma sempre precária e instável se terá desenvolvimento.

Sem dúvida, os defensores das reformas, assim como os propugnadores de um maior planejamento estratégico, têm razão. As duas coisas são necessárias para o desenvolvimento. Mas não é sua falta que nos tem impedido de desenvolver. A res- 
ponsabilidade por isso é essencialmente da política de desenvolvimento com poupança externa e abertura da conta capital, que nos fez perder o controle do preço macroeconômico mais estratégico de uma economia - a taxa de câmbio - e nos levou a duas crises de balanço de pagamentos (1998 e 2002). E da política correlata de taxa de juros básica, que representa uma enorme sangria ao Tesouro Nacional, ao mesmo tempo em que desestimula os investimentos essenciais à retomada do desenvolvimento.

Enquanto a política de crescimento com poupança externa e sua decorrência — taxas de câmbio valorizadas - são fenômenos generalizados na América Latina — só o Chile escapou a essa sina —, a taxa de juros básica, muito acima das taxas de juros praticadas por países com igual ou pior classificação de risco que o Brasil, é uma exclusividade nossa. É a nossa jabuticaba em termos de política macroeconômica. Através dela os rentistas e a ortodoxia convencional montaram no Brasil um paradoxal sistema de subsídios que ultrapassa de longe os incentivos e proteções do tempo do desenvolvimentismo. Podemos considerar que cerca de 7 pontos percentuais é a diferença entre a taxa de juros real Selic (cerca de $10 \%$ ) e a taxa de juros que países de igual classificação de risco pagam (no máximo 3\%). Em última análise, portanto, a diferença de $7 \%$ reais sobre a dívida pública representa um subsídio aos rentistas. O subsídio envolvido nessa 'política monetária', que na verdade é uma política fiscal regressiva, não fica, porém, limitado a esse ponto. Com $10 \%$ de taxa de juros básica, a taxa de juro média do sistema deveria ser aproximadamente de $15 \%$; e a taxa de lucro média das empresas, $20 \%$. Como, entretanto, essa taxa de lucro tem sido no Brasil menos de $10 \%$, estariam inviabilizados todos os investimentos, e a economia entraria em colapso. Entretanto, isso não acontece porque se imaginou um subsídio compensatório para as empresas industriais e de serviços (a Taxa de Juros de Longo Prazo do BNDES) e outro subsídio compensatório para os empresários agrícolas. Sem esses subsídios as transferências aos rentistas seriam impossíveis. Esses dois subsídios compensatórios são, entretanto, essenciais para a sobrevivência mínima do sistema econômico. Não poderão ser reduzidos enquanto o subsídio original não for eliminado. Enquanto isso não acontece, a violência contra o mercado, praticada por seus 'defensores', atinge o paroxismo, e boa parte da elevada carga tributária encontra explicação.

Enquanto não houver mudança nas políticas de câmbio e juros, ao mesmo tempo em que se mantém a política fiscal de redução vigorosa do déficit público, não haverá, portanto, retomada sustentada do desenvolvimento. A economia poderá crescer em alguns anos modestamente, como deve acontecer neste ano, mas esse crescimento será precário.

Há, entretanto, uma boa notícia. O problema da taxa de câmbio foi em grande parte resolvido no Brasil nos últimos dois anos. Não graças a uma política deliberada, mas graças a duas crises de balanço de pagamentos. A depreciação de 1999, decorrente da crise de 1998, foi incompleta e precisou de nova crise, em 2002, 
para que razoavelmente (não plenamente) se resolvesse. Nesse período, graças à depreciação cambial, o país realizou um grande ajuste externo, de quase $5 \%$ do PIB. Um enorme déficit em conta corrente transformou-se em um superávit. Foi a crise cambial que elevou a inflação em 2002; foi a parada da subida do preço do dólar e sua queda parcial em 2003 que permitiram a queda da inflação. Foi essa depreciação que reduziu salários artificialmente elevados e permitiu que nossas importações fossem reduzidas, nossas exportações aumentadas e nossa capacidade de poupança doméstica também aumentada. É essa depreciação, que se mantida nos próximos anos, será a chave para a retomada do desenvolvimento e para que os salários reais voltem a crescer. Não nos enganemos, porém. Para que isto aconteça é preciso que a manutenção de uma taxa de câmbio relativamente depreciada seja algo deliberado, uma estratégia de desenvolvimento - uma estratégia que tem custos no curto prazo, mas, como têm demonstrado os asiáticos, é poderosa no médio prazo.

Por outro lado, é preciso ter a coragem de enfrentar a armadilha da alta taxa de juros básica. A taxa de juros de longo prazo é o mercado financeiro que determina. Já a taxa de curto prazo, a taxa básica do Banco Central, é exógena. Nos termos da política de metas de inflação, o COPOM deve levar em conta as expectativas de taxa do mercado, mas não tem que se submeter passivamente a elas. E certamente não pode nem deve reagir automaticamente a choques cambiais de preço - choques de oferta, portanto - com elevação da taxa de juros, que é uma política para combater inflação de demanda.

Em síntese, a retomada do desenvolvimento pode ocorrer no curto prazo, em um prazo não depende nem de reformas institucionais nem de maior planejamento estratégico, mas, para isso, será necessário mudar a equação macroeconômica perversa de altas taxas de juros e de câmbio ainda valorizado. Só assim poderemos alcançar a verdadeira estabilidade macroeconômica, que não significa apenas estabilidade de preços, mas implica equilíbrio intertemporal das contas externas e fiscais. Para isso, porém, será preciso ter a coragem de enfrentar os interesses dos rentistas e do mercado financeiro e a ortodoxia convencional em que se apóiam.

Sob a pressão das ideologias vindas do Norte, tornou-se inapropriado falar em classes sociais, mas elas continuam mais relevantes do que nunca. O desenvolvimento, hoje, depende de uma grande e informal aliança entre empresários do setor real, técnicos públicos e privados e trabalhadores - ou seja, dos detentores do capital e da capacidade empresarial, do conhecimento técnico e organizacional e da força de trabalho: os três elementos essenciais do desenvolvimento. Uma nação só se constrói quando um acordo desse tipo existe. Um acordo que não impede conflitos internos. Como as famílias, os estados nacionais vivem em permanentes e necessários conflitos internos, mas mantêm entre si uma solidariedade básica que os transforma em uma nação. Uma nação que tem grandes interesses comuns com as demais nações, mas também interesses conflitantes. Uma nação, ou um estado 
nacional, que vive em um sistema global, em que as interdependências são crescentes e colabora para que esse sistema global se torne mais democrático e mais solidário. Uma nação que existe em um sistema globalizado, que se define pela concorrência generalizada em nível internacional das empresas, apoiadas por seus respectivos estados nacionais. Uma nação, portanto, que, ao definir a globalização nesses termos, se dá conta que o conceito de nação tornou-se mais estratégicos do que nunca. Esse é o grande desafio que o Brasil enfrenta: voltar, em termos efetivos e não apenas retóricos, a se autodefinir como nação. 